\title{
MICROBIOLOGICAL SCREENING OF OTORRHOEA FROM PEOPLE COMING TO HOSPITAL IN MAHAJANGA
}

\author{
Rivo Solotiana Rakotomalala ${ }^{1}$, Patrick Randrianandraina ${ }^{2}$, Tsiriniaina Ramavoson ${ }^{3}$, Fiacre Ramisarimanana ${ }^{1}$, \\ Ainamalala Catherine Razafindrakoto ${ }^{3}$, Tahirimalala Rabenandrianina ${ }^{1}$, Davidra Rajaonatahiana ${ }^{4}$, Odilon \\ Tiandaza $^{4}$, Olivat Rakoto Alson ${ }^{5,}$ Andry Rasamindrakotroka ${ }^{5}$, Rasoamialy Razanakolona ${ }^{5}$ \\ ${ }^{1}$ Laboratory of University Hospital Center PZAGA, University of Mahajanga, Madagascar, \\ ${ }^{2}$ ENT Unit, University Hospital Center PZAGA, University of Mahajanga, Madagascar, \\ ${ }^{3}$ Laboratory of University Hospital Center Morafeno, TUniversity of Toamasina, Madagascar, \\ ${ }^{4}$ Faculty of Medecine, University of Mahajanga, Madagascar, \\ ${ }^{5}$ Faculty of Medecine, University of Antananarivo, Madagascar.
}

\section{ABSTRACT}

Background: Otorrhoea commonly hits young people. Ciprofloxacin and rifampicin are the two ear drop antibiotics commonly used for the probabilistic treatment of otitis in Madagascar. This study aimed to determine the potentially dangerous bacteria involved in otitis and to identify their resistance to fluoroquinolone or rifampicin. Method: A prospective study was conducted with the collaboration of the Ear Nose and Throat unit (ENT) at the laboratory of UHC PZaGa in Mahajanga. In whole, 56 patients were included. Samplings of otorrhoea were performed by aspirating the auditory canal using $2 \mathrm{ml}$ sterile syringe and then were headed to the laboratory in less than 30 minutes for analysis. Results: Amidst identified microorganisms were fungus $(4,7 \%)$ and bacteria $(95,3 \%)$ to which Gram-negative bacilli represented 72.1\% $(\mathrm{n}=44)$, Gram-positive cocci $6.4 \%(\mathrm{n}=10)$, Gram-positive bacilli 8.2\% $(\mathrm{n}=5)$ and Gram-negative cocci $3.3 \%(\mathrm{n}=2)$. Among these bacterias, Pseudomonas aeruginosa and Proteus sp were predominant, with respectively $41 \%(n=25), 23 \%(n=14)$. However, three cases of $S$. aureus reported six with negative coagulase Staphylococcus, one with Escherichia coli, one with Klebsiella sp, one with Haemophilus sp, two cases with Neisseria sp and four cases with Corynebacterium sp. Two types of cultures were noticed, one of them monomorphic $(91.1 \%, \mathrm{n}=51)$ and the other polymorphic $(8.9 \%, \mathrm{n}=5)$ to which three associations of $P$. aeruginosa-Proteus $s p, 1$ association of $P$. aeruginosa-coagulase-negative Staphylococcus and one association of $P$. aeruginosa- E. coli. No resistance to ciprofloxacin was observed with Pseudomonas, Neisseria sp. Haemophilus, and enterobacteria except for E. coli. No resistance to rifampicin was observed with $S$. aureus. However, the sensitivity of $S$. aureus to ciprofloxacin decreased (one bacterium out of three). Conclusion: The use of rifampicin or fluoroquinolones should be based on the type of ear infections. Rifampicin is suggested only if $S$. aureus was responsible for otitis. Ciprofloxacin use is still yet sensible to Gram-negative bacilli.

Keywords: Otitis; Bacteria; Rifampicin; Ciprofloxacin.

\section{INTRODUCTION}

Otorrhoea commonly hits young people. Risk factors of otitis occurrence as described by literature, are the presence of smokers among patients [1,2], chronic otorrhoea over twelve months and the number of children living on the same roof [3]. Ciprofloxacin and rifampicin are the two ear drop antibiotics commonly used for the probabilistic treatment of otitis in Madagascar. Discharge in the ear known as otorrhoea is a common reason for medical consultation. Otitis media is an infectious disease widely found around the world. In the United States, it represented $42 \%$ of antibiotic treatment prescribed in ambulatory [4].

The change of behaviour of these pathogens because of antibiotics should lead to new reflexions on how therapy must be conducted [5]. Identifying bacteria involved in otitis media is a prerequisite for possible drugs to be tested to deal with otitis media and later, to do an

\begin{tabular}{ll}
\hline & DOI: $10.31878 /$ ijcbr.2019.61.07 \\
& eISSN: $2395-0471$ \\
\hline &
\end{tabular}

effective probabilistic antibiotic therapy. This study aimed to determine the potentially dangerous bacteria involved in otitis and to identify their resistance to fluoroquinolone or rifampicin.

\section{MATERIAL AND METHODOLOGY}

Study design: Prospective descriptive study

Ethics approval and informed consent: Informed consent was obtained from participants

Time frame: May 2016 to February 2017

Study location: at the laboratory of UHC PZaGa in Mahajanga (Madagascar) with the collaboration of the Ear Nose and Throat unit (ENT)

Inclusion criteria: Including all patients with otorrhoea who accepted to undergo consultation at the ENT unit.

Exclusion criteria: Who are on or past same antibiotic therapy

\section{Sample size: Fifty-six}

Sample collection: Samplings were performed by aspirating the auditory canal using $2 \mathrm{ml}$ sterile syringe;

Correspondence: Dr. Rakotomalala Rivo Solotiana, Head of Medical Laboratory Unit, UHC PZAGA, 401 Mahajanga, Madagascar.E-mail:solorivo@yahoo.fr

(C) Authors; 2020. International Journal of Clinical and Biomedical Research, Sumathi Publications.

This is an Open Access article which permits unrestricted non-commercial use, provided the original work is properly cited. (CC BY-NC-SA 4.0) 
samples were then headed to the laboratory in less than 30 minutes and immediately tested.

Method: A questionnaire was established and completed for each patient at the ENT unit for demographic data. The samples of otorrhoea were collected and sent for following examination at the laboratory where culture media were used: chocolate agar plate, Hektoen agar which is a selective media for Gram-negative rods, Uriselect chromogenic agar to identify bacteria using colour, Mueller Hinton for the antibiogram. Sensitivity test drugs used were Ciprofloxacin $(5 \mu \mathrm{g}$ charge disc, Oxoid, Grande

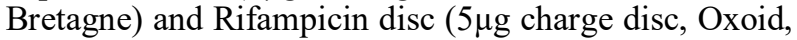
Grande Bretagne).

Day 1: Direct examination, sample inoculation on culture media and incubating at $37^{\circ} \mathrm{C}$ for $24 \mathrm{~h}$;

Day 2: Identification and antibiogram, re-isolation if needed;

Day 3-4: Reading of the antibiogram and results.

\section{RESULTS}

In whole, 56 patients were included with a sex ratio of $0,93(\mathrm{p}>0,05)$. The mean age was 14.74 years old, age range from 2 to 10 years old was predominant $(37,5 \%)$, followed by individuals aged between 11 to 20 years $(21.4 \%)$ then 21 to 30 years $(21.4 \%)$ ( $>>0,05)$. Smokers represented $46.4 \%(n=26 ; p>0,05)$. Patients from urban area were $53.6 \%(n=30 ; p>0,05)$. In descending order, the number of children living on the same roof from 1 to 2 years old was $37,5 \%$, those of 3 to $4(35,7 \%)$, and of 5 or above $(26,8 \%)$. As for the level of education of parents, $44,6 \%$ with primary education, $25 \%$ with secondary education, $16,2 \%$ university and $7,1 \%$ illiterates $(p>0,05)$. Chronic otitis media (COM) were the predominant $(82,2 \%, n=46)$, then AOM (acute otitis media) $(8,9 \%, \mathrm{n}=5)$ and otitis externa $(8,9 \%, \mathrm{n}=5)$. Amidst identified microorganisms were fungus (4,7\%) and bacteria $(95,3 \%)$ to which Gram-negative rods $72,1 \%(n=44)$, Gram-positive cocci $6,4 \%(n=10)$, Grampositive bacilli $8,2 \%(\mathrm{n}=5)$ and Gram négative cocci $3,3 \%(\mathrm{n}=2)$. Among these bacteria, Pseudomonas aeruginosa and Proteus sp were predominant, with respectively $41 \%(n=25), 23 \%(n=14)$. However, three cases of otorrhoea with $S$. aureus were reported, six with negative coagulase Staphylococcus, one with Escherichia coli, one with Klebsiella sp, one with Haemophilus $s p$, two cases with Neisseria $s p$ and four cases with Corynebacterium $s p$. Two cultures were noticed, one of them monomorphic $(91,1 \%, \mathrm{n}=51)$ and the other polymorphic $(8,9 \%, \mathrm{n}=5)$ to which three associations of $P$. aeruginosa-Proteus $s p$, one association of $P$. aeruginosa- coagulase-negative Staphylococcus and 1 association of $P$. aeruginosa- $E$. coli. No resistance to ciprofloxacin was observed with Pseudomonas, Neisseria sp, Haemophilus sp, and Enterobacter $s p$ except for E. coli. No resistance to rifampicin was observed with $S$. aureus. However, the sensitivity of $S$. aureus to ciprofloxacin decreased (one case of three).
Table 1: Bacteria identified

\begin{tabular}{ll}
\hline Germe & N \\
\hline Pseudomonas aeruginosa & $25(41)$ \\
Haemophilus sp & $1(1.6)$ \\
Escherichia coli & $1(1.6)$ \\
Proteus sp & $14(23)$ \\
Corynebacterium sp & $4(6.7)$ \\
Staphylococcus aureus & $3(4.9)$ \\
Negative coagulase Stapylococcus & $6(9.8)$ \\
Enterobacter sp. & $2(3.3)$ \\
Streptococcus sp. & $1(1.6)$ \\
Nesseria sp & $2(3.3)$ \\
Klebsiella sp & $1(1.6)$ \\
Positive Gram Bacillis unidentifiables & $1(1.6)$ \\
\hline
\end{tabular}

Table 2: Ciprofloxacin sensitivity

\begin{tabular}{lll}
\hline & \multicolumn{2}{l}{ Ciprofloxacin test } \\
\cline { 2 - 3 } Bacteria & Sensible & Résistant \\
& $\mathrm{N}(\%)$ & $\mathrm{N}(\%)$ \\
Pseudomonas aeruginosa & $25(100)$ & 0 \\
Proteus sp & $14(100)$ & 0 \\
Staphylococcus aureus & $1(33)$ & $2(67)$ \\
Escherichia coli & 0 & $1(100)$ \\
Enterobacter sp & $2(100)$ & 0 \\
Klebsiella sp & $1(100)$ & 0 \\
Nesseria sp & $2(100)$ & 0 \\
Haemophilus sp & $1(100)$ & 0 \\
\hline
\end{tabular}

Table 3: Rifampicin sensitivity

\begin{tabular}{lll}
\hline \multirow{2}{*}{ Bacteria } & \multicolumn{2}{l}{ Rifampicin test } \\
\cline { 2 - 3 } & Sensible & Résistant \\
Staphylococcus & N $(\%)$ & N $(\%)$ \\
aureus & $3(100)$ & 0 \\
\hline
\end{tabular}

Table 4 : Otorrhoea origin

\begin{tabular}{ll}
\hline Otitis & N (\%) \\
\hline Otitis externa & $5(8.9)$ \\
Acute otiti media & $5(8.9)$ \\
Chronic otitis media & $46(82.2)$ \\
Total & $56(100)$ \\
\hline
\end{tabular}

\section{DISCUSSION}

Otorrhoea is a medical condition with a common reason for ENT consultation. Results showed that there is no significant association between gender and the occurrence of otorrhoea. Authors, in Italia, reported a similar result in which female gender represented 55,6\% [6]. The bacteria involvement is predominant with a monomorphic culture; the association of most pathogenic bacteria is also reported by other authors [7,8]. Pseudomonas aeruginosa that colonise the ears is predominant (Table I). It is the case found by other authors in Niger [9] but in South Africa, it comes in the second position after Proteus sp [10].

As for otitis externa, the common bacteria were Pseudomonas aeruginosa, enterobacteria, 
Staphylococcus aureus and Streptococcus pyogenes. The pool of bacteria reported in the study is similar to the results, but as noted, the predominance of Pseudomonas aeruginosa as causative organisms of otitis externa varies according to studies [11]. In the US, authors reported $37,7 \%$ of Pseudomonas aeruginosa [12].

For acute otitis media, we found $60 \%$ of Pseudomonas aeruginosa. Which is not the case in France, where Husson reported 4,7\% [13]. In France, Haemophilus influenza is the first causative agent of acute otitis media, followed by Streptococcus pneumoniae. AOM is very common, and at least $75 \%$ of children have contracted it before starting school [14].

For the chronic otitis media, a predominance of Pseudomonas aeruginosa and Proteus sp. was found with respectively $40 \%$ and $26 \%$. In India, Tanmoy D. and Debabrata R., reported in 2012, 37\% of Pseudomonas aeruginosa and $17 \%$ of Proteus [15]. But in Mali, the prevalence of proteus $(34,79 \%)$ is much higher than that of Pseudomonas (4,35\%) as reported by a study in 2014[16]. Fluoroquinolone represents the topical treatment of this condition because of its broad antimicrobial spectrum, a well-suited action against more colonising strains and due to its lack of otitis related toxicity [17].

The fungal organisms of otitis are not to be excluded. Causative agents of otitis mycosis belong exclusively to the genus Aspergillus and Candida. The frequently encountered germ in Europe is Candida albicans, followed by Aspergillus niger and Aspergillus flavus. Regarding the use of ciprofloxacin, all bacteria of Pseudomonas aeruginosa were sensitive to the antibiotic. It is also the case in South Africa [9]. But in other countries like Pakistan, sensitivity is reduced, $70,8 \%$ in 2012 [18] and of $37,7 \%$ in Nigeria in 2010 [19]. The sensitivity of $S$. aureus to ciprofloxacin decreased. This phenomenon is due to the gene mutation of the bacteria. The use of a sole therapy of ciprofloxacin enhances the gene mutation favourably. In 2015 , the sensitivity of otitis $S$. aureus found in India was $29,41 \%$ [20]. On the opposite, rifampicin remained the topical drug to treat otitis in the case of $S$. aureus for Madagascar. No resistance was found during the study. As for enterobacteria or pseudomonas, rifampicin is naturally resistant to but ciprofloxacin remains the effective antibiotic for Gram-negative bacillus in case of otitis in Madagascar. Throughout the study, the identification of the otitis associated bacteria is used to guide the anti biotherapy even if the antibiogram fails to come.

\section{CONCLUSION}

In Mahajanga, the most pathogenic bacteria of otorrhoea were primarily Pseudomonas aeruginosa and Proteus $s p$, but fungal involvement is not to be excluded. Indeed, the use of rifampicin or fluoroquinolone must follow indication depending on the type and origin of otitis, knowing that the bacteria mutation and the resistance rate of these bacteria to these antibiotics. Rifampicin ear drop in ambulatory treatment is not advised until $S$. aureus is being identified.
Clinical use of study: Though the size of the sample is limited, these results reflect the benefit of microbiological screening of otorrhoea.

Acknowledgment: We thank the hospital for his support and the people who provided their technical help.

\section{Conflict of interest: Nil}

Source of funding: Nil

\section{REFERENCES}

[1] Sophia A, Isaac R, Rebekah G, Brahmadathan K, Rupa V. Risk factors for otitis media among preschool, rural Indian children. Int $\mathrm{J}$ Pediatric Otorhinolaryngol. 2010;74(6):577-683.

[2] Csákányi Z, Czinner A, Spangler J, Rogers T, Katona G. Relationship of environmental tobacco smoke to otitis media (OM) in children. Int $\mathbf{J}$ Pediatric Otorhinolaryngol. 2012;76(7);p: 989-3.

[3] Vernacchio L, Samuel M. Lesko R, Vezina M. Racial/ethnic disparities in the diagnosis of otitis media in infancy. Int J Pediatric Otorhinolaryngol. 2004:68(6):785-804.

[4] Siddartha, Vadisha B, Satheesh Kumar B, Vijaya $\mathrm{S}$, Rashmi. Otitis Media with Effusion in Relation to Socio Economic Status: A Community Based Study. Indian J Otolaryngol Head Neck Surg. 2012;64(1):56-8.

[5] Gehanno P. Epidémiologie bactérienne et analyse critique des essais thérapeutiques dans l'otite. Méd Mal Infect. 1992;22:114-29.

[6] Martines F, Bentivegna D, Sciacca V, Enrico M. Risk factors for otitis media with effusion: Casecontrol study in Sicilian schoolchildren. Int J Pediatr Otorhinolaryngol 2011;75(6):754-9.

[7] Bayeh A, Mulugeta K. Bacteriology and antimicrobial susceptibility of otitis media at dessie regional health research laboratory, Ethiopia. Ethiop J Health Dev. 2011;25(2): 161-7.

[8] Raghu Kumar KG. A Study of Bacterial Profile and Antibiotic Susceptibility Pattern of Chronic Suppurative Otitis Media among Patients attending a Tertiary Care Centre, Davangere. Sch J App Med Sci. 2014;2(5B): 1606-12.

[9] Oyeleke Solomon. Screening for bacteria agents responsible for otitis media and their antibiogram. Afr J Microbiol Res. 2009; 3(5): 249-52.

[10] Meyer E, Whitelaw A, Edkins O, Fagan J. Chronic otorrhoea: Spectrum of microorganisms and antibiotic sensitivity in a South African cohort. S Afr Med J. 2013; 103(7): 471-3.

[11] Kiakojuri K, Mahdavi Omran S, Bahareh J, Hajiahmadi $M$ and al. Bacterial Otitis Externa in Patients Attending an ENT Clinic in Babol, North of Iran. Jundishapur J Microb. 2016; 9(2):1-5.

[12] Roland P, Stroman D. Microbiology of acute otitis externa. Laryngoscope. 2002; 112(7):1166-77. 
[13] Husson M O, Vincent C. Étude de l'épidémiologie bactérienne de l'otite moyenne aiguë de l'enfant observée en ville dans la région Nord Pas-deCalais. Pathol Biol. 2001;49: 789-93.

[14] Vergison A, Dagan R, Arguedas A. Otitis media and its consequences: Beyond the earache. Lancet Infect Dis. 2010;10(3):195-203.

[15] Tanmoy D, Debabrata R. A Study of the Bacteriological Profile of Chronic Su54ppurative Otitis Media in Agartala. Indian J Otolaryngol Head Neck Surg. 2012; 64(4): 326-9.

[16] Sacko H, Diallo A O. Bactériologie de l'otite moyenne suppurée chronique de l'enfant au Mali. J Tun ORL. 2014; 31(1):34-36.
[17] Pessey JJ, Ovetchkine P, Dumarcet N. Antibiothérapie locale en ORL Recommandation de bonne pratique. Médecine thérapeutique. 2004;10(5):356-9.

[18] Muhammad I. Chronic suppurative otitis media: frequency and sensivity pattern of Pseudomonas aeruginosa. Journal of Medical Science 2012; 20 (4):181-3.

[19] Egbe C, Mordi R, Omoregie R, Enabulele O. Prevalence of Otitis Media in Okada Community, Edo State, Nigeria. Mac J Med Sci. 2010;3(3): 299-302.

[20] Kailash W, Shubhangi g. Bacterial and fungal study in chronic suppurative otitis media from a developing country. Int J Mod Trends Sci Technol. 2015;16(1):104-8. 